\title{
Seasonal Changes in a Population of Pseudanopthalmus tenuis (Coleoptera, Carabidae) in Murray Spring Cave, Indiana: A Preliminary Report.
}

by

\author{
James H. KEITH*
}

\section{INTRODUCTION}

The question of seasonal reproductive cycles in troglobitic organisms is one that has been raised many times, but has, until comparatively recently, received very little data by way of an answer. (See Barr, 1968; Culver, 1971; Jegla and Poulson 1970; Poulson, 1963 and Vandel, 1965; pp.380-382).

It has been proposed that, given the relative constancy of the cave environment (constant darkness, minimal temperature and relative humidity fluctuations), those organisms, both aquatic and terrestrial, that are adapted to the cave environment would exhibit little or no reproductive seasonality (Bedel and Simon, 1875 in Vandel, 1965: p.381). On the other hand, the fluctuations that do occur in the cave environment, however slight, may be sufficient to serve as cues for reproduction and other seasonal activities in troglobitic organisms. It has been noted that flooding in caves seems to control the seasonal reproduction of some aquatic troglobites by triggering reproduction (Hawes, 1939 and Poulson, 1963) and to cause the modification of reproductive behavior in other aquatic troglobites in order to cope with the flood, as suggested by the work of Culver (1971).

Flooding may give seasonal cues to terrestrial troglobites since, in caves where flooding does occur, it is predictable (occurring mainly in winter and spring in temperate regions) and may exert profound changes in the physical parameters of the cave by lowering the air temperature, increasing the relative humidity and depositing sediment (Cropley, 1965; Poulson, 1964 and Burr, 1968). It may also seasonally renew the energy supply of the cave by transporting and depositing organic debris (Poulson, 1964 and Barr, 1968).

It may be pointed out that while the majority of aquatic troglobites seem to exhibit seasonal reproductive cycles, terrestrial troglobites exhibit both seasonal and nonseasonal reproduction. (See Poulson, 1964 and Vandel, 1965. p. 381 for summaries.) The question, then, must be not only whether an organism exhibits a seasonal reproductive cycle or not, but what cues, if any, exist in its environment to maintain the cycle.

\section{STUDY AREA AND FAUNA}

Murray Spring Cave (Fig. 1) is situated just east of Paoli, Indiana in the lower Ste.

\footnotetext{
* Department of Zoology, Indiana University, Bloomington, Indiana 47401, U.S.A.
} 
Genevieve Limestone (Indiana Geological Survey, 1966). A map prepared by Ritter (1969) indicates that the cave has about $486 \mathrm{~m}$ of passage. Much of its length consists of walking stream passage flanked by high mud banks. The final $90 \mathrm{~m}$ of passage becomes progressively lower and eventually the stream siphons. The main passage is intersected at several points in the ceiling by a high, narrow canyon passage (not shown in Fig. 1) which is largely inaccessible. The entrance of the cave is situated at the head of a collapsed spring alcove. The stream water exits at the base of this collapse and feeds a small surface pond.

The entrance collapse is responsible for the large deposits of mud seen throughout the cave. Flood water, slowed at the collapse, backs up into the cave and deposits silt, clay and organic debris along its length, leaving mud banks up to $4 \mathrm{~m}$ high. Stream water subsequently undercuts these banks in some areas, causing them to slump. This leaves a network of cracks in the mud in which Pseudanophthalmus and other organisms spend much of their time. Flood waters seldom reach the ceiling, except at two low points near the entrance, and at the back of the cave.

Pseudanophthalmus tenuis (Barr, 1960 and Krekeler, 1958), a troglobitic trechine beetle, is the largest and one of the most abundant organisms found in the terrestrial arthropod fauna of Murray Spring Cave. Its length ranges from 4.1 to 6.0 $\mathrm{mm}$ in length in this cave. Its diet, as determined by observations of unconfined beetles in Murray Spring Cave, consists of collembolans (3 observations), small obligochaetes ( 2 observations), diplurans ( 1 observation) and immature diplopods (2 observations). It is preyed upon by the salamander Eurycea lucifuga (as determined by examining salamander feces) and by spiders such as Meta menardi and larger specimens of Phanetta subterranea. In the latter case, the webs of these spiders may contain as many as four dead beetles at one time. Occasionally, the beetles may prey upon one another (single field observation in Murray Spring Cave).

The beetles have three identifiable stages after emergence from pupation. The first is a teneral stage,which characterizes newly emerged beetles. These have a very characteristic butter yellow color, a low weight-to-length ratio and, in the females, undeveloped ovaries. After about a month (field observations on tenerals penned in the cave and fed regularly), the head and pronotum become reddish-brown while the elytron remains light. These partly sclerotized, or late teneral beetles do not seem to differ from tenerals, except in coloration. The time of transition from a late teneral to an adult beetle is unknown. Adult beetles are uniformly reddishbrown in color, are heavier than tenerals or late tenerals and females have ovaries in various stages of development.

The larval development of these beetles is virtually unknown. Two larvae have been collected from Murray Spring Cave, both about $1 \mathrm{~m}$ above normal stream level on the mudbanks. One found on May 18, 1973 was $3 \mathrm{~mm}$ long and one found on June 29, 1973 was $6.5 \mathrm{~mm}$ long. Both were found on trips made while the cave stream water was receding after flooding. Efforts to keep these alive proved unsuccessful and both died within a week of capture. It was noted, however, that the two larvae both showed burrowing activity when penned in containers of cave mud. It was also noted that their movements were sluggish both in the pen and in the cave when they were collected. 
Pseudanophthalmus will retreat into cracks and crevices when touched or disturbed. However, a constant vibration of the mudbank, such as by repeated thumping with the fist, causes many beetles to leave their refuge und retreat up the mudbank to the rock wall or ceiling above. It is conceivable that this flight constitutes a survival mechanism by which the beetles avoid being trapped by flood waters which probably disturb the mudbanks in a manner similar to thumping on the mudbank.

The author was informed by Dr. Karl Krekeler (personal communication) that another species of Pseudanophthalmuus, P. youngi (See Barr, 1960 and Krekeler, 1958), also inhabits the cave. Only two specimens have appeared in the collections

(4) Indicates ceiling height in feet
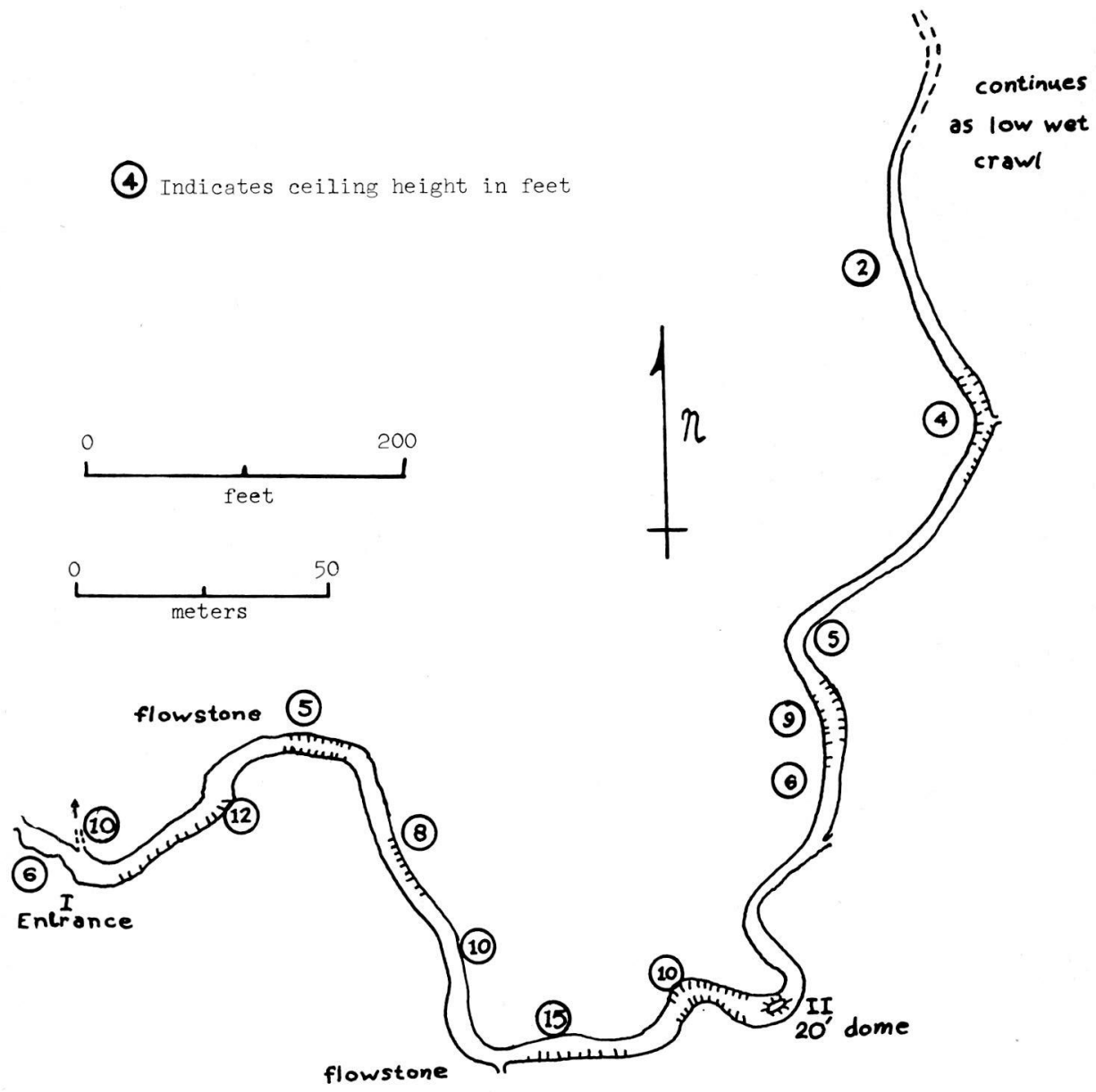

Fig. 1. Map of Murray Spring Cave (From Ritter, 1969). 
made in that cave since February, 1973. This corresponds to a frequency of about 0.025 for this species during that period. Since these species cannot be easily differentiated in the field and since $P$. youngi occurs in such a low frequency, the data presented are considered to represent $P$. tenuis only.

\section{METHODS}

The cave is visited at weekly or semiweekly intervals, flood conditions permitting, and all field data are gathered at these times. Water levels are read at staff gages set at I and II (Fig. 1). Water level for the day is read directly and tempera paint applied to the side of the gages permits interim high water levels to be read as well.

Population estimates are obtained by using both a mark-recapture method and censusing of $9 \mathrm{~m}^{2}$ plots ( $2 \mathrm{~m}$ wide $\times 4.5 \mathrm{~m}$ long). Initially, 26 stations were set up along the passage at $15.2 \mathrm{~m}$ intervals. At each station a pitfall trap baited with cheese and kidney was used to collect beetles for the mark-recapture study. Censusing was conducted at 8-12 $9 \mathrm{~m}^{2}$ plots chosen randomly along the mudbanks. Due to flooding of the traps and possible bait bias, this method was abandoned and the traps removed at the end of June. This was replaced by an alternate system. At each station a $9 \mathrm{~m}^{2}$ area ( $2 \mathrm{~m}$ wide $\times 4.5 \mathrm{~m}$ long) is delineated. The plot is then searched and the beetles captured with an aspirator sexed, marked and released for recapture. These plots are also used for the visual census. At the end of June the number of stations was reduced from 26 to 24 due to the extreme difficulty in reaching the last two stations.

Marking consists of a series of up to four dots applied to the elytron of the beetle in four colors of automobile touchup paint using a 4/0 paint brush. The dots indicate at which station and which month the beetles were originally captured and marked. Population estimates are calculated monthly using the Petersen Index $\mathrm{P}=$ $\mathrm{Mn} / \mathrm{m}$, where $\mathrm{M}$ is the number of marked animals released from the first sample; $\mathrm{n}$ is the number of animals in the second sample; $m$ is the number of marked animals in the second sample and $\mathrm{P}$ is the estimated population. Standard deviations for the estimates are calculated by the formula S.D. $=\sqrt{\frac{M^{2}(n+1)(n-m)}{(m+1)^{2}(m+2)}}$

(See Roff, 1973).

The visual censuses are recorded as the number of beetles $/ \mathrm{m}^{2}$ for all plots censused (CENSUS in Table 1 and Fig. 2). In order to compare these with the population estimates, the estimates are also expressed as beetles $/ \mathrm{m}^{2}$ using as estimate of $1288 \mathrm{~m}^{2}$ of mudbank area for the cave (EST in Table 1 and Fig. 2).

For laboratory study, 6-10 beetles are collected once each month and placed in $70 \%$ ethanol. The beetles are blot dried and the females dissected under a $15 \mathrm{x}$ dissecting microscope to determine the condition of the ovarioles and ovaries. Any eggs present are counted and measured. Weight is expressed as milligrams $/ \mathrm{mm}$ of length to correct for size differences among the beetles. The number of individuals of the fungus Laboulbenia subterranea Thaxter, which infests these beetles (Dr. R.K. Benjamin, personal communication to Dr. Michael Tansey) is determined and 
expressed as the number of individuals/beetle. It is reasoned that the degree of fungal infestation of the beetle population is, in part, a function of time so that changes in the age structure of the population may be indicated by changes in the degree of infestation of the beetles.

\section{RESULTS}

Table 1 presents the results of this study presented as monthly averages. Aspects of between station variation will be discussed in later papers.

\section{Water Level Fluctuations}

It can be seen from Table 1 that the water level was high in the winter and spring. From February through April, the cave was flooded much of the time, allowing only three trips to be made into the cave during that period. From May through August, the water level was nearly always low. The indicated high water levels during this period were a result of sudden thunderstorms rather than long-term flooding. No flooding occurred in September and October, but in November and December the cave began flooding for increasingly longer periods of time as the rainfall increased.

\section{Population Fluctuations}

Fig. 2 is a composite graph of columns $1,3,4,6,7,12$ and 13 of Table 1 . The rise in population shown by the EST curve in Fig. 2a may reflect a reinvasion of the cave mudbank area by the beetles, possibly from the relatively dry canyon passage above the stream. The EST curve peaks in July and then begins to fall rapidly. The ratio of estimated to censused beetle densities represents the number of beetles actually occupying the mudbank relative to the average number of beetles foraging. This ranges from 14.2 in July to 1.9 in October. The CENSUS curve changes little but gradually rises through the fall indicating that beetles are spending more of their time on the surface of the mudbank. This rise coincides in time with a pulse of late teneral beetles whose average weight-to-length ratio is much lower than that of adults ( 0.65 vs. 0.90 , respectively). Since the late tenerals are lighter in weight, it is probable that they have lower food reserves and would spend more time, relative to adults, on the mudbanks foraging for food.

The curve labelled FUNGI (Fig. 2b) suggests that the adult beetle population turns over every year. The hypothesis, that changes in the population age structure will be reflected in changes in the degree of fungal infestation, is supported from July onward when the first tenerals appear and the adults begin to die off, as suggested by the drop in the EST curve. The initial drop in infection incidence, from May through June, may be due to a general migration to the mudbanks by beetles that are less infected. Lindroth (1948) has shown that the transmission of infection in the Laboulbeniaceae seems to depend, for the most part, on contact with spore-containing soil. If there is a component of the beetle population that spends a large proportion of its time during the winter in the canyon passage of that 


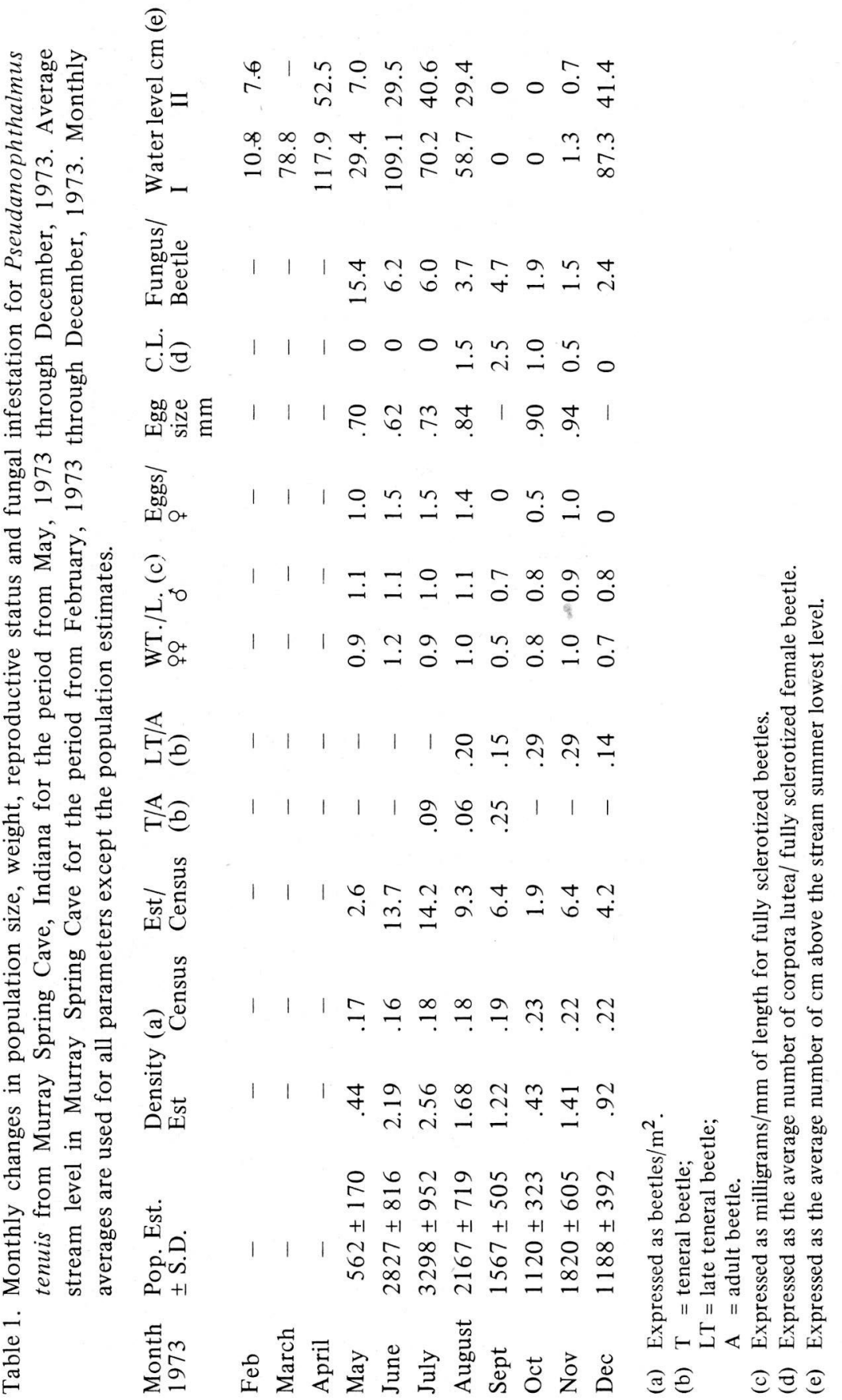


cave, where there is often much less soil due to the passage configuration, this component might be expected to have a lower infection rate than one which spends its time moving to and from the mudbanks between periods of high water. A general migration back to the mudbank area, then, would serve to lower the overall infection rate.

The pattern of teneral appearance also suggests a yearly population turnover. Tenerals first appear in July and continued to appear until September. The time from the first teneral appearance until the first late teneral appearance is one month, which agrees with observations of penned teneral beetles. It seems to take a longer time for late teneral beetles to attain adult coloration. In October, the collection contained male Pseudanophthalmus with normal adult coloration but lightly sclerotized aedeagi. This suggests that it takes a minimum of two months for late teneral to assume adult coloration. This suggestion is further supported by the observation that late tenerals persist in the population roughly twice as long as tenerals (Fig. 2c).

\section{Evidence for Annual Population Turnover}

The monthly pattern of egg length and number and the number of corpora lutea per female beetle is consistent with an annual population turnover. In sexually mature female beetles, eggs ranging from 0.2 to $1.0 \mathrm{~mm}$ in length are found. To serve as a scale of reference, eggs that are $0.75 \mathrm{~mm}$ in length or greater are considered to be mature while the others are in various stages of development. The presence of corpora lutea (Marsh, 1969: p.37) is noted and the number is expressed as the average number per female beetle. The presence of corpora lutea in the ovaries indicates that eggs have been laid and the ovaries spent.

It can be seen that the average number of eggs per mature female beetle and the average egg length (Table 1) increase until August when the first egglaying begins as indicated by the presence of corpora lutea (See Fig. 2c). After that time, the average egg size increases while the average number of eggs per mature female beetle decreases due to the development of the smaller eggs and an increase in the number of eggs laid. As many as seven eggs in various stages of development have been found in a single female. However, the average number of eggs per gravid female beetle (as opposed to the average number of eggs for females with adult coloration, as shown in Table 1) is about three. The lack of eggs in December is due to the fact that all of the females collected had either undeveloped ovaries and adult coloration, or were late tenerals, indicating, most likely, that those with adult coloration had recently been late tenerals.

The weight-to-length ratio varied both with the month and the period of egglaying. The ratios were averaged only for beetles with adult coloration. Table 1 indicates that the weight of the beetles remained fairly constant until August when it begins to decrease. In the case of the female beetles, this drop coincides with the release of eggs. In the males, however, there is obviously no egglaying to account for the drop in weight. This weight loss may be accounted for in the males and, in part, in the females, by increased competition for food brought about by an influx of immature beetles into the mudbank system. This competition may, in turn, explain the drop in the EST curve and the rise in the CENSUS curve of Fig. 2, a 
2a. Estimated and censused population densities.

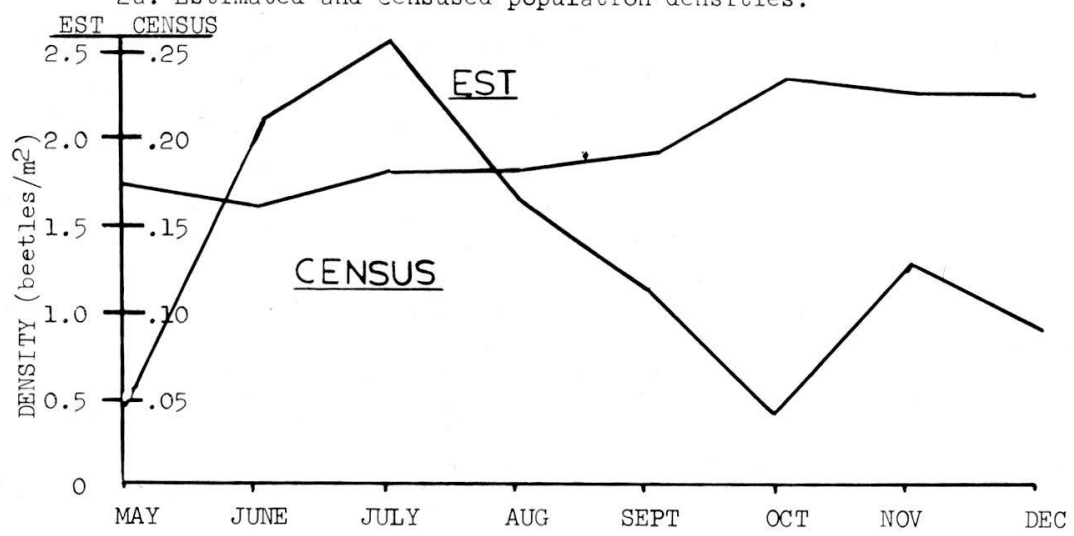

$2 b$. Fungal infestation.

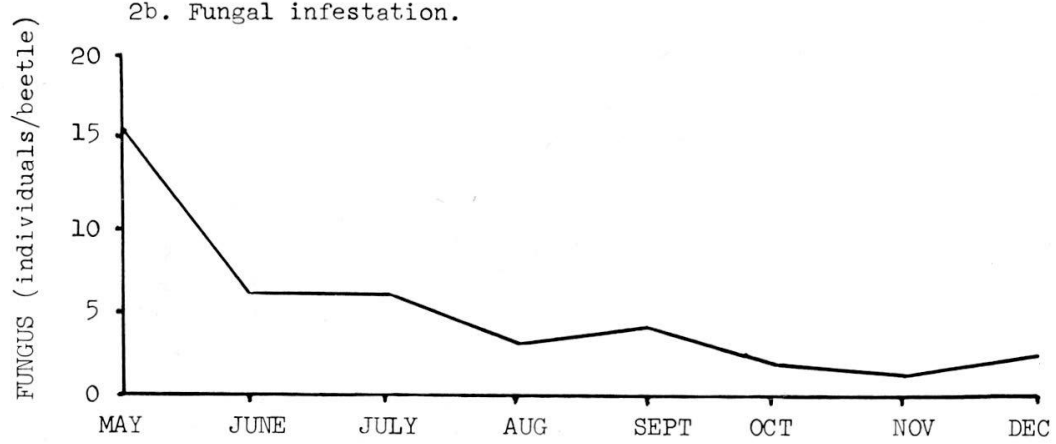

2c. Corpora lutea and teneral and late teneral frequencies.

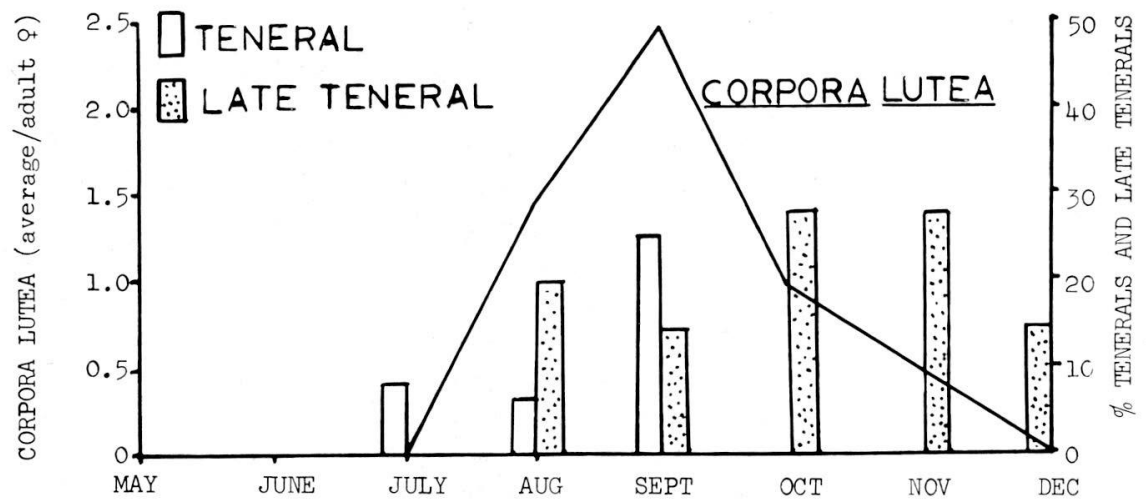

Fig. 2. Monthly changes in population size, fungal infestation, number of corpora lutea and teneral and late teneral frequencies for Pseudanophthalmus tenuis from Murray Spring Cave, Indiana from May, 1973 through December, 1973. 
decrease in total numbers due either to mortality caused by starvation or an emigration to other areas, and an increase in the number of foraging beetles. Since teneral and late teneral beetles are somewhat translucent, it is a simple matter to observe the condition of their guts in the field. A full gut is characterized by a black spot under the elytron. Field notes indicate that about $80 \%$ of the tenerals and late tenerals had full guts during the period from September-November. Laboratory dissections for that same period reveal that less than $40 \%$ of the adult beetles had full guts and that the guts of the rest of the adult beetles contained only a small amount of unidentifiable greenish-black material. It must be noted here that these observations must be interpreted with caution. When handled, the beetles usually regurgitate a small amount of material. It has not yet been shown whether this completely empties the gut or not.

\section{DISCUSSION}

From the data presented, it appears that Pseudanophthalmus tenuis exhibits a rather well-defined seasonal reproduction. The beetles emerge from pupation in summer and begin feeding. In late summer and early fall the female adults in the population lay eggs and after this, the adults begin to die off rapidly. By December, practically all of the population consists of those beetles which had emerged the preceding summer. These become sexually mature by the following summer, breed, lay eggs and die. The eggs laid hatch some time prior to May and the larvae undergo an unknown number of instars. These pupate and begin to emerge as tenerals in July.

The cumulative late teneral frequency (Table 1) can be seen to be about $100 \%$. If the population size remains constant from year to year, this would indicate that there is a complete yearly turnover of the adult population. The discrepancy between the cumulative frequencies of the tenerals and late tenerals $(40 \%$ vs. $107 \%)$ can be explained by the observation that tenerals are more secretive than late tenerals and adults (Poulson and Kane, personal communication).

It also appears that the mudbanks of Murray Spring Cave is only one of the habitats occupied during the year and that the drier parts of the cave are inhabited during periods of flooding. The prey of Pseudanophthalmus tenuis can be classified, for the most part, as detritivores (Barr, 1968). Census of the tops of mudbanks, which are rarely covered by floodwaters, reveal a nearly constant population of collembolans while the lower, often flooded mudbank areas are generally completely lacking in these species after floods (personal observations). Repopulation of the lower areas seems to take about 1-2 weeks, provided new flooding does not occur. The same censuses reveal that beetles are rarely found on the tops of mudbanks but will quickly reappear on the lower mudbank areas after flooding subsides. Two strategies are suggested here:

1) A beetle may attempt to "commute" between the mudbank areas and the upper levels during periods of flooding and low water. This would increase its chances of finding suitably prey, but on the other hand, the prey species available 
would be diminished and the energetic cost of "commuting" may be rather high when compared with the amount of energy it receives from foraging on the mudbank. In addition, its probability of being infected by Laboulbenia subterranea would be enhanced by intimate contact with the cave soil. While the Laboulbeniaceae seem to have no directly deleterious effect on infected beetles (Lindroth, 1948), they are found on every part of their body, including the legs, mandibles and antennae (personal observations). Infection by Laboulbenia subterranea may, therefore, reduce the beetles, foraging efficiency by interfering with its movements and sensory and feeding activity.

2). A beetle may spend the greater portion of the flooding period in the upper level passages. While one would expect to find few, if any, suitable prey species in this area, the beetle may survive by ingesting mud washed down from the surface through joints in the limestone. It has been noted repeatedly (personal communication, Thomas Kane and personal observations) that penned beetles, in the absence of food will ingest mud or sand from the substrate. Personal observations have shown that the beetles can survive for a considerable amount of time on this diet (three months or more), presumably feeding on bacteria and other microflora and -fauna. (See Vandel, 1965; pp. 330-346). The energy intake would be low, but on the other hand, the cost of obtaining food would also be low. In addition to this, these beetles would be expected to have a lower rate of fungal infection, since they would have less contact with cave soil.

It seems that both strategies are being employed in Murray Spring Cave. It is seen that beetles are abundant on the mudbank even after flooding. After the winter and spring flooding subsides, however, there is an increase in the number of beetles present and a corresponding drop in fungal infection (Table 1 and Fig. 2), which suggests the introduction of a different component of the beetle population into the mudbank environment. Traps set on the tops of the mudbanks have caught no beetles, which indicates that they are not spending an appreciable length of time on the mudbank tops, even during floods.

No matter which of these strategies is employed, the net effect would be to lower the beetles' overall energy intake during winter and spring flooding. Since Pseudanophthalmus is basically predatory, it would require a better diet than the organisms derived from ingesting mud in order to be reproductively successful. Prolonged occupation of the mudbanks by both Pseudanophthalmus and its prey would then be required, a situation which is possible only during the summer and fall. The discovery of beetle larvae immediately after heavy flooding coupled with their relative immobility and burrowing activity indicates that the larvae probably can and do survive in the mudbank during the winter and spring. Pupation and emergence in this environment during the summer would then insure the teneral beetles an adequate and immediately available food supply.

The fall decline in numbers of the adult beetles can probably be best explained by saying simply that the adults have reached the end of their life span. If this is true, then it is highly unlikely that Pseudanophthalmus tenuis survives for much more than a year after emergence. Since many carabid beetles can live up to four years (Arnett, 1960), this would seem to be an exception to the findings of other 
investigators that show that troglobitic organisms have a greater life span than their epigean relatives (Poulson, 1964 and Vandel, 1965: p.370).

The seasonal reproductive cycle of Pseudanophthalmus tenuis, then, is closely attuned to seasonal changes of the mudbank environment. The mudbanks harbor a large population of prey species for Pseudanophthalmus, due to the large amounts of mud and organic debris deposited by flood waters. However flooding, which is quite predictable, removes many of the prey species from the mudbanks and denies the beetles access to the mudbanks for appreciable periods of time. During these periods, the beetles must survive on a diminished diet. There is no evidence to show that the beetles are remaining on the unflooded mudbank tops or exploiting the nearly constant numbers of prey items found there. Rather, they seem to be leaving the mudbank areas entirely during periods of flooding. During the summer and fall months, when flooding is virtually nonexistant, the beetles are able to occupy the mudbanks and feed and reproduce there. The larvae probably stay on the mudbanks and emerge in the summer when there is no significant danger of being washed out or isolated from their food supply.

\section{ACKNOWLEDGEMENTS}

I would like to thank Dr. John M. Emlen for his advice and assistance throughout this study and for his helpful review and criticism of this manuscript. Dr. Michael Tansey gave valuable advice pertaining to the fungus Laboulbenia subterranea and enabled the author to have it positively identified. Thanks are also due to Dr. Thomas L. Poulson and Thomas C. Kane for their advice and criticism of this manuscript and for the opportunity to share ideas with them concerning all phases of this project. Special thanks are extended to the following people for their assistance in the field: Mark Eliot, Roscoe Ellis and Michael Moore. Expenses for this study have been, in part, defrayed by a Doctoral Grant-in-Aid provided by Indiana University.

\section{SUMMARY}

A study of a population of Pseudanophthalmus tenuis is being conducted in Murray Spring Cave, Orange County, Indiana as one facet of a larger research project encompassing the entire terrestrial community of that cave. Changes in behavior and abundance determined by census and mark-recapture methods and physiological changes determined from field-collected beetles indicates that these animals exhibit a seasonal reproductive rhythm probably mediated or controlled by winter and spring flooding of the cave. 


\section{RESUME}

Parmi les différents aspects abordés dans un vaste programme de recherche portant sur l'ensemble de la communauté terrestre de la Murray Spring cave, Orange county, Indiana, celui de l'étude d'une population de Pseudanophthalmus tenuis est en cours. Les changements physiologiques (déterminés à partir d'individus pris sur le terrain) et ceux dans le comportement et l'abondance (déterminés par dénombrements directs et une méthode de recapture d'individus marqués) montrent que ces animaux possèdent un rythme saisionnier de reproduction, probablement influencé ou contrôlé par les inondations de la grotte en hiver et au printemps.

\section{REFERENCES}

Arnett, R. H. 1960. The Beetles of the United States (A Manual for Identification). Washington, D.C. The Catholic University of America Press. 1112 p.

Barr, T. C., Jr. 1960. A synopsis of the cave beetles of the genus Pseudanophthalmus of the Mitchell Plain in Southern Indiana. (Coleoptera, Carabidae). Amer. Midl. Nat. 63: 307-320.

1968. Cave ecology and the evolution of troglobites. Evol. Biol. 2: 35-102.

Cropley, J. B. 1965. Influence of surface conditions on temperatures in large cave systems. Bull. Nat. Speleol. Soc. 27: 1-10.

Culver, D. C. 1971. Analysis of simple cave communities III. Control of abundance. Amer. Midl. Nat. 85: 173-187.

Hawes, R. S. 1939. The flood factor in the ecology of caves. J. Anim. Ecol. 8: 1-5.

Indiana Geological Survey. 1966. Drilling record and analysis of SDH 150. Calcar Quarry, Orange County, Indiana.

Jegla, T. C. and T. L. Poulson. 1970. Circannian rhythms-I. Reproduction in the cave crayfish, Orconectes pellucidus inermis. Comp. Biochem. Physiol. 33: 347-355.

Krekeler, C. H. 1958. Speciation in cave beetles of the genus Pseudanophthalmus (Coleoptera, Carabidae). Amer. Midl. Nat. 59: 167-189.

Lindroth, C. H. 1948. Notes on the ecology of Laboulbeniaceae infesting carabid beetles. Svensk Botanisk Tidskrift 42: 34-41.

Marsh, T. G. 1969. Ecological and behavioral studies of the cave beetle Darlingtonea kentuckensis Valentine. (Coleoptera: Carabidea). University of Kentucky. Ph.D. Thesis.

Poulson, T. L. 1963. Cave adaptation in amblyopsid fishes. Amer. Midl. Nat. 70: 257-290. 1964. Animals in aquatic environments: animals in caves. in: D. B. Dill ed. Handbook of Physiology, sect. 4, "Adaption to the environment" ch. 47: 749-771. Washington. Amer. Physiol. Soc.

Ritter, C. D. 1969. Murray Spring Cave. Bloomington Indiana Grotto Newsletter 8: 63-64.

Roff, D. A. 1973. On the accuracy of some mark-recapture estimators. Oecologia 12: 15-34.

Vandel, A. 1965. Biospeleology: The Biology of Cavernicolous Animals. New York. Pergamon Press. 524 p. 